\section{Age and task effects in short-term memory of children}

\author{
KAREN KEELY* \\ University of Western Australia, Nedlands, Western Australia, Australia
}

Children of 4,8 , and 14 years performed a visual memory task with easy- or hard-to-label displays and with or without repetition of stimuli over trials. Eight pictures were displayed in serial order, and the task was to find the card in the array that matched an identical probe card. Performance improved with age, and strong serial position effects were obtained for all ages and tasks. In contrast to previous studies, primacy effects were obtained for the youngest children tested. Task difficulty increased with difficulty of labeling and with repetition, but order of task difficulty remained the same for all ages. The d' measure, borrowed from signal detection theory, revealed differences in criterion levels over serial position, which in earlier studies had been confounded with strength of memory.

Serial presentation of visual material employing a card game technique has been used in several studies of short-term memory in children and adults. Cards depicting familiar objects are shown one at a time and laid face down in order of presentation from left to right before the $S$. The task is to point to the position of the correct card on being shown a probe card that matches only one of the cards displayed.

Atkinson, Hansen, and Bernbach (1964), using eight cards randomly selected from a set of 12 different animal pictures, found that 5-year-olds scored a higher proportion of correct first-choice responses over all serial positions than did 4-year-olds. Both groups showed recency effects but no primacy effect, which, the authors maintain, characterizes the performance of adult Ss on this task.

Calfee, Hetherington, and Waltzer (1966) varied the display size $(3,4$, or 5 animal cards from a set of 11) and obtained strong recency effects for 4-year-olds on all list lengths. A slight primacy effect found in early trials later disappeared.

The general shape of the serial-position curve changes as a function of labeling. Bernbach (1967) instructed one group of 5-year-olds to use simple names for four hard-to-label colors, which were presented in four-, six-, or eight-item displays. A reverse probe technique was used. The task was to select the appropriate color from a circular array to match that of an indicated face-down card. Although lower than a comparison group of college students, the serial-position curve for the 5-year-old label

\footnotetext{
*This study is the first stage of an investigation for a PhD thesis. I gratefully acknowledge the help and advice of my supervisor, Professor John Ross, at all stages in the preparation of this paper.
}

group showed the three characteristics of adult performance: near-perfect performance on the most recent item, a slight " $S$ " shape, and primacy effects. The no-label group showed a simple position function like the $S s$ in Atkinson et al's study. Bernbach concluded that the use of labeis enables rehearsal and makes the child's performance more like that of the adult.

Donaldson and Strang (1969) criticized the earlier studies for failing to take into account the popularity of each serial position. The frequency with which Ss chose each position in the array had been confounded with the accuracy of these choices. Using a corrected measure of performance, "the proportion of all choices of $\mathrm{n}$ which are correct choices," they reanalyzed Atkinson et al's data and presented their own to demonstrate that a primacy effect was present in the performance of all age groups, including the youngest children tested. This is in strong disagreement with the earlier studies which report that primacy effects characterize the performance of adults only.

In addition to the problem of position preference, for which Donaldson and Strang provided a correction, a further methodological difficulty remains and must be dealt with before any sensible comparisons can be made. The problem is that of possible differences in criterion levels for different serial positions, which normally go undetected. Such criterion differences make results ambiguous and may falsely suggest a difference in memory strength for different positions in the array.

The $d^{\prime}$ measure, adapted from signal detection theory, has been used by Murdock (1966) in studies of serial position effects. It gives an index of the strength of memory which is independent of criterion and, as Murdock has shown, also exposes criterion variations. Since performance on the four tasks to be used in the present study will depend on both the criterion for each position and the strength of memory for that position, it seems advisable to use the $d^{\prime}$ measure here and account for both aspects of the response.

The aim of the present study was to explore the differences in the performance of 4-, 8-, and 14-year-old children on a serial memory task, similar to the card game already mentioned.

In view of the reported age differences and the effects of labels on performance, this investigation introduces four task variations which allow closer examination of specific variables, such as ease of labeling the pictures, and the effects of repeating the stimuli from one trial to the next. Since older children are supposed to use labels more and hence have greater opportunity to improve performance on early items, the nature and extent of primacy and recency effects for the three ages on the four tasks were of particular interest.

\section{Subjects}

\section{METHOD}

Twelve males and 12 females acted as Ss in each of the three age groups: (1) mean age $=14$ years, 2 months; $(2)$ mean age $=8$ years, 6 months; (3) mean age $=4$ years, 6 months. The children were taken from the upper classes in their year at school and, where IQ scores were not available, were selected by teachers as having above average ability. The youngest children were taken from the Western Australian University kindergarten and were rated as bright by their teacher. All children were screened for color blindness on the Ishihara test.

\section{Materials}

Four stimulus tasks were used in the study: (I) 8 easy-to-label shapes repeated; (2) 8 colors repeated; (3) 64 easy-to-label shapes, not repeated; and (4) 64 hard-to-label shapes, not repeated. The easy-/hard-to-label classification was established in a pilot study using children from each of the age ranges used in the present study. In all three age groups, Ss used more words in the label and took significantly longer to begin naming the hard-to-label items.

The easy-to-label objects in Tasks 1 and 3 were simple black-on-white drawings (e.g., cat, apple, house) and the hard-to-label stimuli were nonsense shapes. The eight colors were easily identified by all Ss (i.e., blue, green, yellow, red, pink, brown, orange, white). 

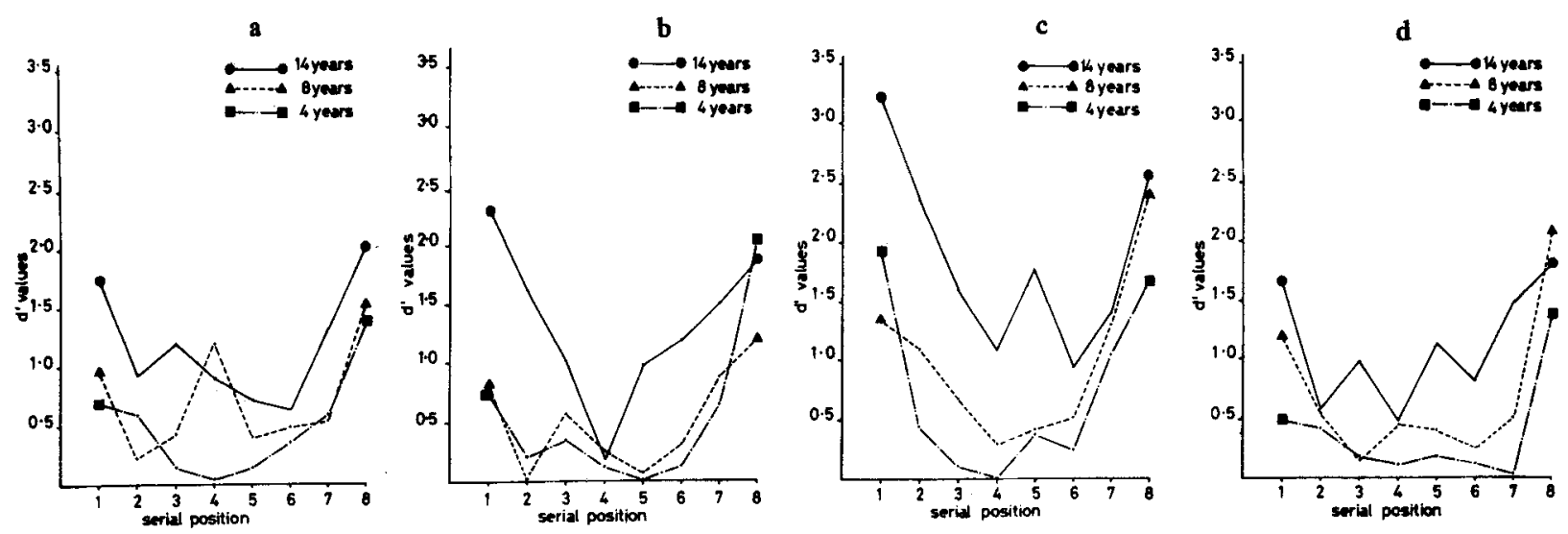

Fig. 1. $\mathrm{d}^{\prime}$ values indicating strength of memory over serial position for three age groups of children. Serial Position 8 is the most recent item presented in all cases. (a) Task 1: 8 repeated easy-to-label shapes; (b) Task 2: 8 repeated colors; (c) Task 3: 64 easy-to-label shapes; (d) Task 4; 64 hard-to-label shapes.

The eight repeated stimulus objects in Tasks 1 and 2 were balanced across serial position so that on all test trials each of the eight pictures appeared in a different place. A new shape appeared in each serial position on every trial for Tasks 3 and 4 .

\section{Apparatus}

The Ss sat about $35 \mathrm{~cm}$ from a display board inclined at approximately $15 \mathrm{deg}$ away from the perpendicular. Eight windows $(5.5 \times 11.0 \mathrm{~cm})$ were spaced $1.75 \mathrm{~cm}$ apart in a horizontal array, and each was covered by a metal shutter which could be pushed down to display the picture. Electric counters were attached to the eight shutters, recording the time (in $0.1 \mathrm{sec}$ ) that elapsed before each serial position was chosen.

A series of cardboard slides, each containing eight pictures or colors, was used to present the stimuli in the windows.

\section{Procedure}

Each $S$ did all four tasks, and task order was balanced within each age group. There were two practice and eight test trials for all tasks. To ensure that 4-year-olds understood instructions, correct first choices were rewarded with a cent or a sweet.

The Ss were tested individually by the same $E$ in two sessions, each lasting about $20 \mathrm{~min}$. Instructions were as follows:

"I am interested in finding out about the way people remember things. This morning I am going to show you some pictures/colors in each of these windows here. I will open each window for a couple of seconds, and after you have had a look, I will close the shutter and go on to the next one, and so on, to the end of the row. There will be something different in each window. Your job is to have a good look at each window as I open the shutter. Then, when I come to the end of the row, I will place a card in front of you showing you one of the pictures/colors you have just seen. Your job is then to find the one that is the same as this card. You are to push down the shutters [E demonstrates] uncovering the one you think it is. Leave the shutter down so you can see which picture/color you have uncovered.

"If your first try is not correct, don't worry. Leave the shutter down and have another try. Keep on going until you find the one that is the same as the card I put in front of you. I will then change the pictures/colors and you have another go. Any questions? I'll give you a couple of practices first to get you used to the idea."

The E recorded latencies to each position chosen, and the first-choice responses were extracted for future analysis.

\section{RESULTS}

The classical serial-position effect $(F=12.353, \quad \mathrm{df}=7,462, \quad \mathrm{p}<.001)$ is shown in the bow-shaped curves for the three ages on nearly all tasks (Fig. 1). Performance improves significantly with age $(F=36.832, \mathrm{df}=2,66, \mathrm{p}<.001)$, and the separation of age functions is maintained over most serial positions. The nature of the task significantly effects performance $(F=8.866, d f=3,198$, $\mathrm{p}<.001$ ). Ss have greatest difficulty when stimuli are hard to label, i.e., Task 4 , and some difficulty when the stimulus objects

Table 1

Average Criterion Levels Over Serial Position on Four Tasks for 4-, 8-, and 14-Year-Old Children

\begin{tabular}{|c|c|c|c|c|c|}
\hline & $\begin{array}{c}\text { Serial } \\
\text { Position }\end{array}$ & $\begin{array}{l}\text { Task } 1 \\
8 \text { Easy } \\
\text { Shapes }\end{array}$ & $\begin{array}{c}\text { Task } 2 \\
8 \text { Colors } \\
\end{array}$ & $\begin{array}{c}\text { Task } 3 \\
64 \text { Easy } \\
\text { Shapes }\end{array}$ & $\begin{array}{c}\text { Task } 4 \\
\text { 64 Hard } \\
\text { Shapes } \\
\end{array}$ \\
\hline $\begin{array}{l}14 \\
\text { Year } \\
\text { Olds }\end{array}$ & $\begin{array}{l}1 \\
2 \\
3 \\
4 \\
5 \\
6 \\
7 \\
8^{*}\end{array}$ & $\begin{array}{l}1.42 \\
1.24 \\
1.18 \\
1.31 \\
1.51 \\
1.42 \\
1.51 \\
1.67\end{array}$ & $\begin{array}{l}1.88 \\
1.42 \\
0.81 \\
1.34 \\
1.42 \\
1.73 \\
1.61 \\
1.67\end{array}$ & $\begin{array}{l}2.26 \\
1.56 \\
1.51 \\
1.31 \\
1.47 \\
1.38 \\
1.42 \\
2.26\end{array}$ & $\begin{array}{l}1.98 \\
1.24 \\
0.97 \\
1.02 \\
1.56 \\
1.15 \\
1.47 \\
2.26\end{array}$ \\
\hline $\begin{array}{c}8 \\
\text { Year } \\
\text { Olds }\end{array}$ & $\begin{array}{l}1 \\
2 \\
3 \\
4 \\
5 \\
6 \\
7 \\
8\end{array}$ & $\begin{array}{l}1.51 \\
1.38 \\
1.24 \\
1.51 \\
1.07 \\
1.28 \\
0.97 \\
1.42\end{array}$ & $\begin{array}{l}1.35 \\
1.18 \\
1.12 \\
1.07 \\
1.04 \\
1.12 \\
1.56 \\
1.61\end{array}$ & $\begin{array}{l}1.89 \\
1.42 \\
1.24 \\
0.97 \\
1.09 \\
1.15 \\
1.31 \\
2.52\end{array}$ & $\begin{array}{l}1.61 \\
1.38 \\
1.12 \\
1.12 \\
1.07 \\
0.92 \\
1.31 \\
2.10\end{array}$ \\
\hline $\begin{array}{c}4 \\
\text { Year } \\
\text { Olds }\end{array}$ & $\begin{array}{l}1 \\
2 \\
3 \\
4 \\
5 \\
6 \\
7 \\
8\end{array}$ & $\begin{array}{l}1.35 \\
1.56 \\
1.24 \\
1.02 \\
0.83 \\
1.02 \\
1.56 \\
1.47\end{array}$ & $\begin{array}{l}1.56 \\
1.35 \\
1.42 \\
0.92 \\
0.67 \\
1.51 \\
1.47 \\
1.38\end{array}$ & $\begin{array}{l}1.73 \\
1.61 \\
1.27 \\
0.99 \\
0.81 \\
1.21 \\
1.61 \\
1.47 \\
\end{array}$ & $\begin{array}{l}1.28 \\
1.80 \\
1.56 \\
1.04 \\
0.60 \\
1.04 \\
1.35 \\
1.47\end{array}$ \\
\hline
\end{tabular}

*most recent 

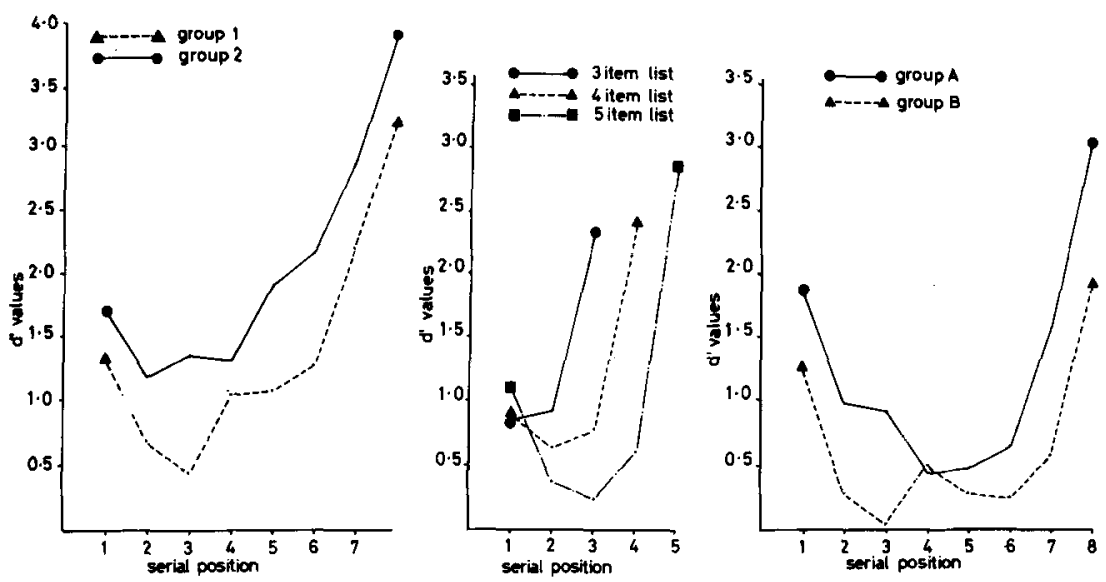

Fig. 2. Results of previous studies reanalyzed in terms of the d' measure: (a) Atkinson, Hansen, \& Bernbach's (1964) study. Group 1, 4 years; Group 2, 5 years. (b) Calfee, Hetherington, \& Waltzer's (1966) study with 3-, 4-, and 5-item lists. (c) Donaldson \& Strang's (1969) study. Group A, 4 years; Group B, 5 years.

are repeated, i.e., Tasks 1 and 2 . The easiest appears to be Task 3 , where a new easy-to-label shape is presented in each serial position on every trial.

There is no significant interaction between task and age, which means that the order of task difficulty does not change over age. The Task by Serial Position interaction is only marginally significant $(\mathrm{F}=1.557, \mathrm{df}=21,1386, \mathrm{p} \doteq .05)$.

Performance changes over serial position as a function of age ( $F=2.781$, $\mathrm{df}=14,462, \mathrm{p}<.001$ ). The 14-year-olds, more often than the 8- and 4-year-olds, show greater accuracy for early rather than late serial positions. The younger children are generally better at remembering the last card shown. This tendency is so marked for the 4-year-olds in Task 2 that their accuracy at Serial Position 8 exceeds that of the two older groups.

While the serial position effects in the experiment are very strong, and while the three ages differ in serial-position effects, there is no significant interaction between age, serial position, and task effects.

False alarm rates were determined for the three age groups, and criterion levels for each serial position are shown for the four tasks in Table 1. Criterion levels are expressed as deviation values from the mean of the "noise" distribution.

\section{DISCUSSION}

A determination of memory strength for serial position, using a $\mathrm{d}^{\prime}$ measure, reveals the existence not only of very consistent recency effects but also primacy effects for all ages on a variety of tasks. While the primacy effect increases with age, it is not absent even at the youngest age level, i.e., 4 years.

Additional support for this finding is the presence of primacy effects in other studies when their results are reanalyzed (Fig. 2). Atkinson, Hansen, and Bernbach (1964), Calfee, Hetherington, and Waltzer (1966), and Donaldson and Strang (1969) present data in sufficient detail to enable reanalysis using the $\mathrm{d}^{\prime}$ measure and, once again, marked recency and smaller but persistent primacy effects emerge for the young children over a variety of tasks and list lengths. The consistency of these primacy effects in the results for young children suggests that their absence in earlier studies was simply an artifact of the measures used, and it no longer seems advisable to refer to such effects as characteristic of adult performance.

The increase in primacy effects with age, seen in the present Age by Serial Position interaction, may on first consideration be taken as support for Bernbach's (1967) labeling hypothesis, which states that older rather than younger Ss use labels spontaneously and therefore have greater opportunity to rehearse and remember the early items in a list. If this was so, we would, in addition, have expected an interaction between age, serial position, and task, since ease of labeling the stimuli was a task variable specifically built into this study and one which the analysis showed did significantly affect task difficulty. No such interaction was found, which contradicts Bernbach's hypothesis. The marginally significant Task by Serial Position interaction suggests that labeling and other task characteristics may change the serial-position effect, but not differently for different ages. The constant order of task difficulty shows that repetition of the same eight stimuli and the use of hard-to-label pictures depressed the performance of each age group in a similar way, which casts further doubt on the usefulness of the labeling hypothesis to account for age differences in performance.

It was noted earlier that possible changes in criterion levels over serial position are considered to be a very serious source of confusion in the results of earlier studies. Table 1 indicates clearly that such changes did occur in this study; Ss change criterion levels according to age and the position of the target card in the array, e.g., younger children show much greater readiness to choose cards in the middle. All Ss are more cautious about choosing end cards in the display and, whenever they do, are more likely to be correct.

The $\mathrm{d}^{\prime}$ analysis successfully exposes these variations in criterion levels, which are considered important in determining performance over serial position for different ages. Its use in short-term memory studies of this kind is recommended.

\section{REFERENCES}

ATKINSON, R. C., HANSEN, D. N, \& BERNBACH, H. A. Short-term memory with young children. Psychonomic Science, 1964, 1, 255-256.

BERNBACH, H. A. The effect of labels on short-term memory for colors with nursery school children. Psychonomic Science, 1967, 7, 149-150.

CALFEE, R. C., HETHERINGTON, E. M., \& WALTZER, P. Short-term memory in children as a function of display size. Psychonomic Science, 1966, 4, 153-154.

DONALDSON, M., \& STRANG, H. Primacy effect in short-term memory in young children. Psychonomic Science, 1969, 16, $59-60$.

MURDOCK, B. B. The criterion problem in short-term memory. Journal of Experimental Psychology, 1966, 72, 317-324.

(Accepted for publication September 14, 1970.) 